\title{
ELECTROLUMINESCENCE FROM RARE EARTH ACTIVATED MATERIALS - NEW CONCEPTS*
}

\author{
M. GoDLEWSKI \\ Institute of Physics, Polish Academy of Sciences \\ 02-668 Warszawa, Al. Lotników 32/46, Poland
}

\begin{abstract}
The recent progress in the field of thin film electroluminescence devices is reviewed. The mechanisms responsible for rare earth excitation in high electric field electroluminescence structures are explained. A new mechanism including rare earth ionization is described. Processes limiting electroluminescence efficiency are also discussed.
\end{abstract}

PACS numbers: 71.55.Eq, 71.55.Gs, 78.50.Ge

\section{Introduction}

The characteristic property of rare car: $\mathrm{RE}$ ) ions is unfilled $4 f$ shell, which is screened from environment by external $5 s, 5 p$ shells (Fig. 1). $4 f$ electrons of trivalent ion extend less than $50 \%$ of $\mathrm{RE}^{3+}$ ionic radii. Strong localization and screening cause that crystalline environment weakly perturbs $4 f$ shell. In consequence, sharp, atomic-like $4 f-4 f$ transitions are observed, which are insensitive to ambient temperature. This and a rich structure of energy levels explain why RE ions are attractive candidates for emission activators in optoelectronic devices.

There are two approaches for obtaining light mission by passing current through a semiconductor (SC) (Fig. 2). The first is by injection of minority carriers at a forward biased $p$ - $n$ junction. The sccond utilizes electroluminescence (EL) excitation by electrons accelerated by high electric ficld applied to an active layer (high-field EL). The latter method is appropriate for wide band gap II-VI SCs, for which construction of $p-n$ junction is difficult. It found practical application for preparing transition metal (TM) or RE activated thin film EL (TFEL) devices operating at ac high electric field (ACTFEL). The first (powder $\mathrm{ZnS}$ phosphor) EL device was constructed by Destriau [1] in 1936. The first TFEL device was obtained by Inoguchi et al. in 1974 for Mn doped $\mathrm{ZnS}$ [2].

In this paper the EL excitation mechanisms and competing nonradiative recombination processes will be described. The present status of ACTFEL research will be reviewed.

*This work was partly supported by the grant no. 204769101 of the Committee for Scientific Research. 


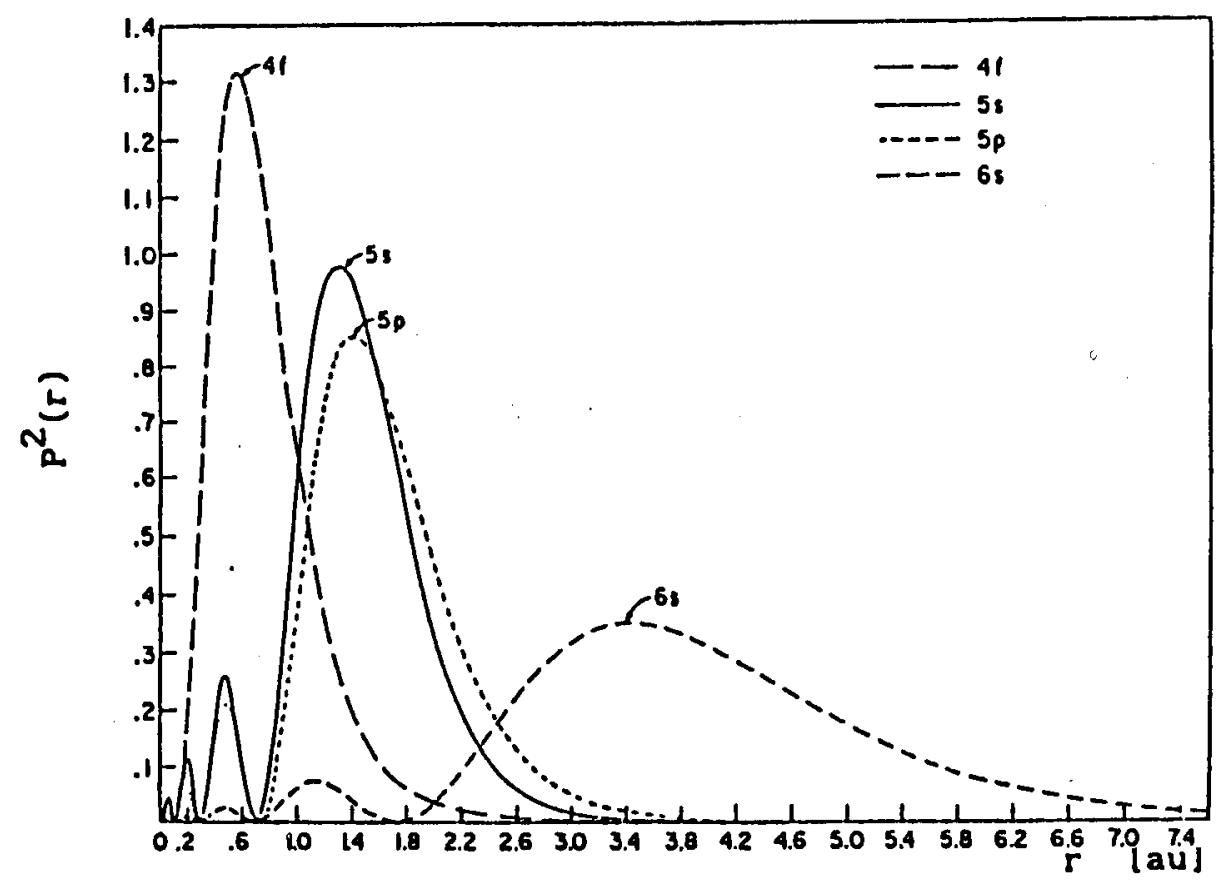

Fig. 1. Electron density of $4 f, 5 s, 5 p$ and $6 s$ wave functions of $\mathrm{Gd}^{3+}$ ion given in the Freeman and Watson atomic units $(1 \mathrm{au}=0.529172 \AA)$.
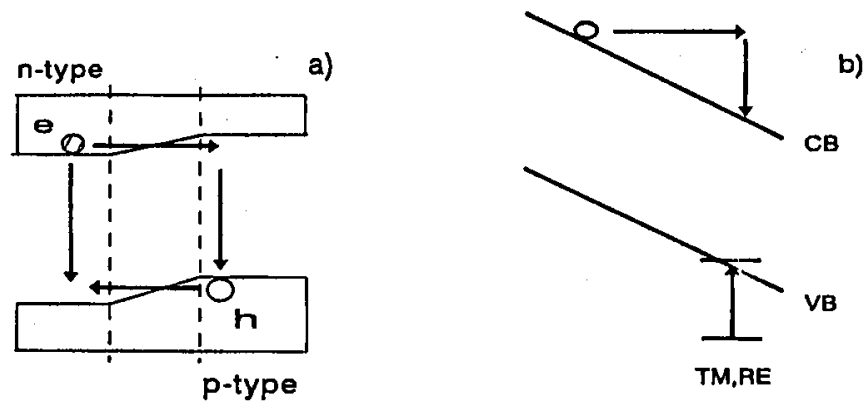

Fig. 2. The basic principle of low (a) and high (b) electric field electroluminescence device.

\section{ACTFEL devices}

ACTFEL devices manufactured now are MISIM (metal-insulatorsemiconductor-metal) structures of the type shown in Fig. 3. EL is induced in either $\mathrm{Mn}$ or $\mathrm{RE}$ doped thin layer of $\mathrm{ZnS}, \mathrm{CaS}$ or $\mathrm{SrS}$ imposed between the di- 
electric layers $\left(\mathrm{Al}_{2} \mathrm{O}_{3}\right.$ or $\left.\mathrm{Al}_{x} \mathrm{Ti}_{y} \mathrm{O}_{2}\right)$ and transparent front and back electrodes. There are two possible ways of obtaining multicolor EL. First of them requires preparation of separate EL phosphors for red, green and blue color. The second alternative bases on filtering of white color EL from either Pr or Eu and Ce doped $\mathrm{CaS}, \mathrm{SrS}$. Thus, for multicolor emission either layered color structures, patterned filter or patterned phosphor structures are prepared.

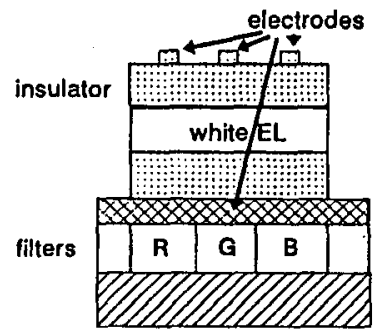

a)

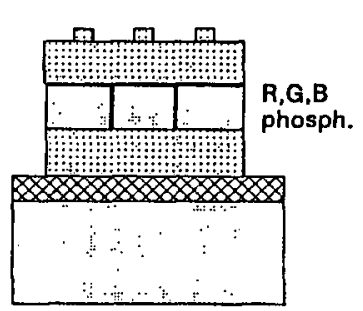

b)

Fig. 3. The schematic diagram of multicolor ACTFEL devices for patterned filter (a) or patterned red (R), green (G) and blue (B) phosphor (b) structures.

TABLE

Comparison of the standards for first and second generation of ACTFEL devices with luminances of laboratory devices.

\begin{tabular}{l|l|c|c}
\hline \hline EL color & $\begin{array}{l}\text { Pixel luminance } \\
\text { in }\left[\mathrm{cd} / \mathrm{m}^{2}\right]\end{array}$ & $\begin{array}{c}\text { Exp. pixel luminance } \\
\text { at 60 IIz in }\left[\mathrm{cd} / \mathrm{m}^{2}\right]\end{array}$ & Material \\
\hline \multirow{2}{*}{ red } & 1-st gen. -42 & 75 & $\begin{array}{c}\text { ZnS:Mn (red filter) or } \\
\text { SrS,CaS:Eu; ZnS:Sm }\end{array}$ \\
\cline { 2 - 4 } & 2-nd gen. -60 & - & ZnS:Tb (lumocens) \\
\hline \multirow{2}{*}{ green } & 1-st gen. - 104 & $90(1990)$ & - \\
\cline { 2 - 4 } & 2-nd gen. -150 & $120(1992)$ & $\mathrm{SrS}: \mathrm{Ce}$ \\
\hline \multirow{2}{*}{ blue } & 1-st gen. - 12 & $4.5(1990)$ & $\mathrm{ZnS/SrS:Ce}$ \\
\cline { 2 - 4 } & 2-nd gen. -17 & $10(1992)$ & $\mathrm{SrS:CeF} 3+\mathrm{CuBr}_{2}$ \\
\hline \multirow{2}{*}{ white } & 1-st gen. -35 & $20-30(1992)$ & $\mathrm{SrS}: \mathrm{Eu}, \mathrm{Ce}, \mathrm{K}$ \\
\cline { 2 - 4 } & 2-nd gen. -50 & $55(1990)$ & $\mathrm{SrS}: \mathrm{Ce}, \mathrm{K}, \mathrm{Eu}$
\end{tabular}

The rapid progress in the field of ACTFEL is documented by the data collected in Table [3-6]. The technical standards for the first and second generation of full color ACTFEL devices are compared with the best pixel luminances of laboratory devices (measured at $60 \mathrm{~Hz}$ ) reported in 1990 and 1992. The most perspective materials for red, green, blue and white EL are listed. Two of the listed devices are now commercially available: yellow-orange EL from $\mathrm{ZnS}: \mathrm{Mn}$ and green EL from $\mathrm{ZnS}: \mathrm{Tb}$. 


\section{RE excitation mechanisms}

\subsection{DAP-RE energy transfer}

In photoluminescence (PL) or cathodoluminescence (CL) $4 f-4 f$ intra-shell or $5 d-4 f$ intra-ion emissions of RE ions can be induced by the energy transfer from excited donor-acceptor pairs (DAPs) to RE sites (Fig. 4) [7]. In the process free

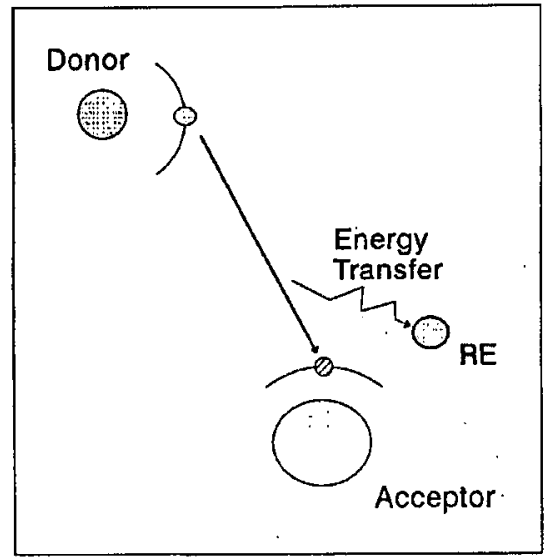

Fig. 4. Rare earth activation mechanism due to energy transfer from nearby donor-acceptor pair.

electrons and holes induced by photoexcitation or by impact of hot electrons (CL) are trapped by donor and acceptor centers. DAP centers decay nonradiatively transferring their excess energy to nearby RE ions [8]. The DAP-RE transfer is the most effective RE excitation process in the CI phosphors. However, in the ACTFEL structures the DAP-RE transfer mechanism is inefficient [9]. IIigh electric field present in the device prevents electron trapping by donor species and ionizes shallow centers when occupied. IIaving in mind high efficiency of the above mechanism it is tempting to propose introduction of some deeper donors, which may stabilize electrons even at high electric fields. In [10] and $\mathrm{Cl}$ [11] should be tried to enhance DAP-RE transfer mechanism in ACTFEL devices.

\subsection{Impact excitation mechanism of $E L$}

Mechanism of EL excitation in TFEL structures was explained by Krupka [12]. TM, RE ions are excited by collision with electrons accelerated by high electric field (Fig. 5a). Cross-sections for the process are rather low $\left(10^{-18} \div 10^{-20} \mathrm{~cm}^{2}\right)$. The efficiency of the process is also reduced by competing one-center Auger transition shown in Fig. 5b. The Auger process is exactly a reverse process to impact excitation, i.e., if the latter is efficient, the former will also be efficient. IIigh efficiency of two Auger processes shown in Fig. 5 was confirmed experimentally $[13,14]$. 


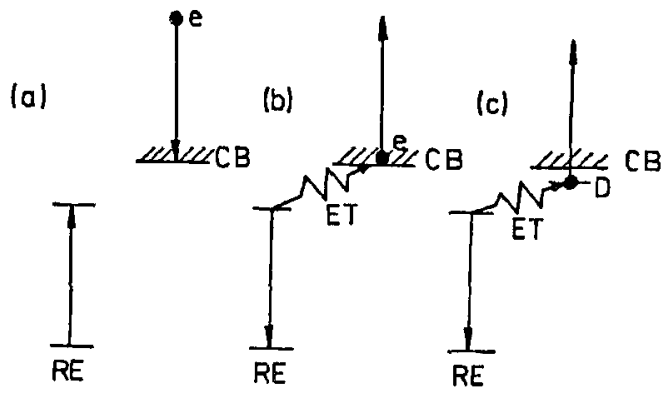

Fig. 5. Impact excitation mechanism of EL in ACTFEL structure (a). In (b) and (c) the competing one-center (b) and two-center (c) Auger processes are depicted. RE (TM) ion decays nonradiatively due to energy transfer to either free (b) or bound (c) electron.

The efficiency of impact excitation process can be increased in a very intuitive way by increasing geometrical size of RE centers. It was shown that RE molecules introduced to the SC matrix (lumocens $[15,16]$ ) can have much larger impact cross-sections than those of isolated ions. The relevant results are shown in Fig. 6a, b. It was found that for $\mathrm{ZnS}$ : Tb the best luminance is obtained for $\mathrm{F} / \mathrm{Tb}$
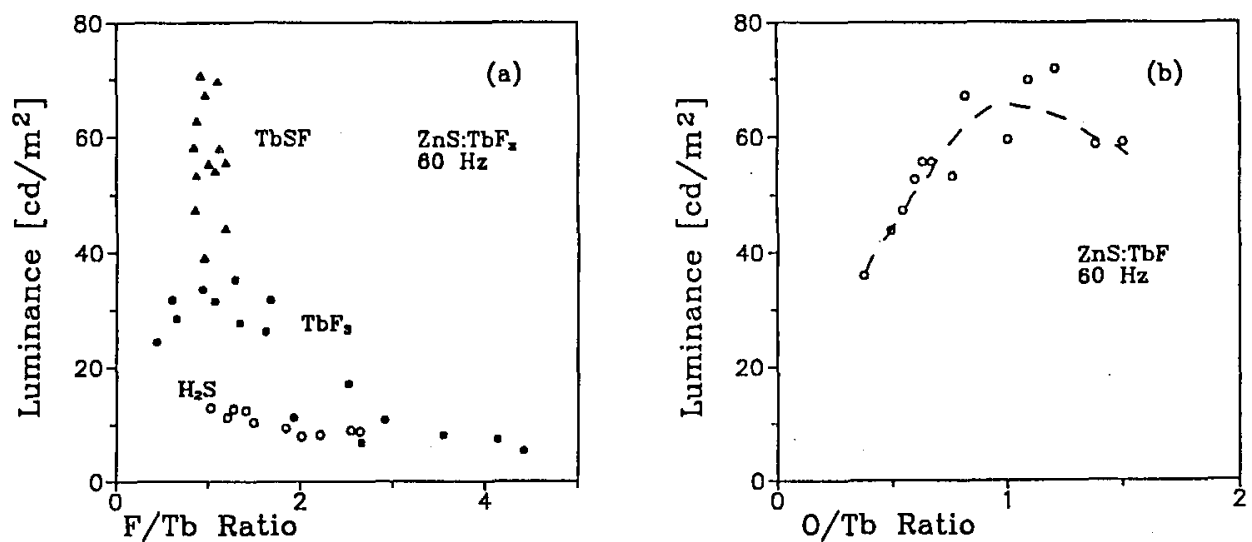

Fig. 6. Dependence of green $\mathrm{Tb}$ luminance from $\mathrm{ZnS}: \mathrm{Tb}$ on the $\mathrm{F} / \mathrm{Tb}$ (a) and $\mathrm{O} / \mathrm{Tb}$ (b) ratios in EL active layer (after [18]).

ratio close to 1 [17]. Exceptionally good luminances were obtained for TbSF and TbOF molecules [18]. It was also shown that a good luminance of atomic layer epitaxy $\mathrm{ZnS}$ doped with metallic $\mathrm{Tb}$ is related to formation of $(\mathrm{TbO})_{n}^{+}$molecules in the layer [19]. The TbOF and TbSF molecules are neutral. Oxygen (sulphur) and fluorine compensate trivalent charge state of RE ion. All spectroscopical properties of $\mathrm{Tb}$ may then be related to molecule properties rather than to properties of $\mathrm{ZnS}$ host lattice. 


\subsection{Impact ionization mechanism of EL}

Recently another mechanism of EL excitation was proposed [20]. In the process $\mathrm{RE}$ emission is excited by collision with hot electrons, which results in $\mathrm{RE}$ ionization (Fig. 7). The ionized RE ion can retrap carrier via an excited $4 f$ or $5 d$

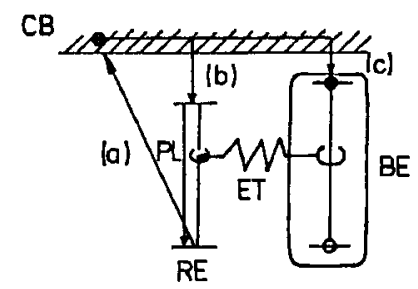

Fig. 7. The sequence of steps of impact ionization mechanism of $R E$ excitation. It includes ion ionization by collision with hot electron (a) followed by fast carrier retrapping via an excited state of RE ion (b). In (c) a new scenario for three step excitation process is shown. First step is RE ionization. Carrier trapping proceeds via an extended state of an ion (bound excitonic state), which (third step) is followed by bound exciton-RE $4 f$ states energy transfer.

state, which is followed by RE emission. A large increase in the EL efficiency was expected, since ionization cross-sections are up to four order in magnitude larger than the impact excitation rates [20]. Moreover, the increase in the excitation efficiency is not accompanied by the increase in the Auger transition rate. The competing Auger process remains the same as for the impact excitation mechanism.

\section{Ionization transitions of $\mathrm{RE}$ ions}

The experimental results for Pr doped $\mathrm{ZnS}$ and $\mathrm{SrS}$ [21, 22] and the electron spin resonance (ESR) investigations of Eu doped SrS [23] indicated that impact ionization mechanism is feasible for RE doped EL structures. This was confirmed by recent photo-ESR and PL excitation investigations of Eu in ZnS [24, 25], Yb in $\mathrm{ZnS}$ [26], $\mathrm{Sm}$ in $\mathrm{ZnS}$ [27], $\mathrm{Tm}$ in $\mathrm{ZnS}$ [28], Eu in $\mathrm{ZnSe}$ [29] and $\mathrm{Eu}$ in $\mathrm{CaS}$ and $\mathrm{SrS}[30,31]$. Experimentally determined energies of $3+/ 2+$ ionization allowed to predict the energies for other RE ions in wide band gap sulfides and selenides. The theoretical two-zigzag curve shown in Fig. 8 was calculated [32-35] with a refined spin pairing theory (RESPET) of Jörgensen [37]. RESPET is a semi-empirical theory based on a well justified linear dependence of ionization energy on number of $4 f$ electrons (denoted by $q$ ) [36], which approximates RE ionization energy by

$$
\Delta E_{\mathrm{II}-\mathrm{III}}=W+q(E-A)+\Delta E_{\mathrm{MC}} \text {. }
$$

$W$ in Eq. (1) is an ionization energy of a free RE ion reduced by the negative electrostatic potential energy at the ligand, polarization energy caused by ionization transition and by lattice relaxation energy. 


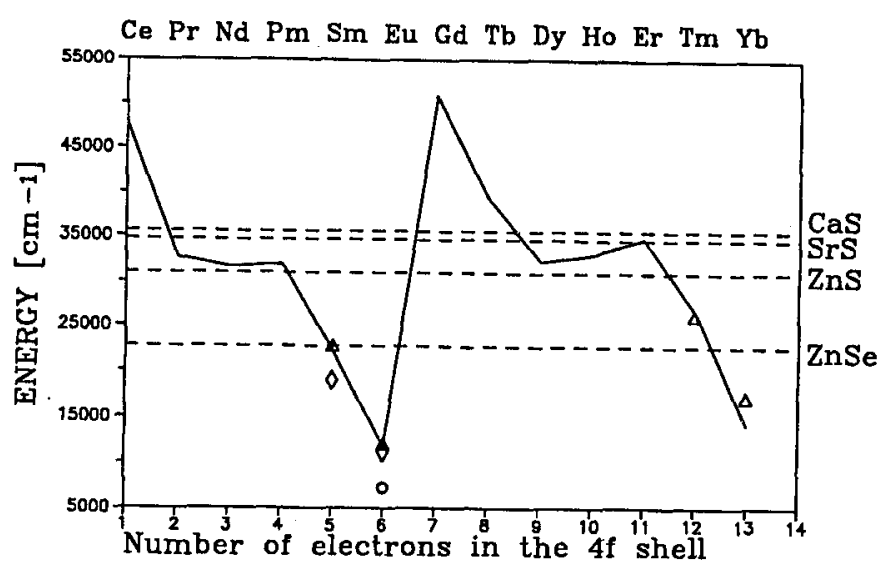

Fig. 8. $3+/ 2+$ ionization energies of lanthanides in wide band gap sulfides and selenides. The solid two-zigzag curve presents the theoretical fit to the experimental data for sulfides with a semi-empirical RESPET theory of Jörgensen. The experimental data shown $(\mathrm{ZnS}-\triangle, \mathrm{ZnSe}-\mathrm{O}, \mathrm{SrS}-\diamond)$ were obtained from either direct photo-ESR studies ( $\mathrm{Sm}$ in $\mathrm{SrS}, \mathrm{Eu}$ in $\mathrm{ZnS}, \mathrm{SrS}$ and $\mathrm{ZnSe}, \mathrm{Yb}$ in $\mathrm{ZnS}$ ) or from indirect $\mathrm{PL}$ excitation measurements (Sm and $\mathrm{Tm}$ in $\mathrm{ZnS}$ ).

$(E-A)$ describes linear modification of the $\Delta E_{\mathrm{II}-\mathrm{III}}$ by regular $Z$ (atomic number)- and $q$-dependent increase in the energy due to contraction of the RE ionic radius and increase in the effective nuclear charge felt by $4 f$ electrons, caused by change of intra $4 f$ screening and, finally, regular $q$-dependent increase in $4 f$ interelectronic repulsion.

$\Delta E_{\mathrm{MC}}$ describes a multiplet correction, since the ionization transition proceeds not between barycenters of each $4 f^{q}$ manifold but from the ground state of the initial charge state to the ground state of the final charge state of RE ion.

The applicability of the above theory was tested by comparing ionization energies of RE ions in different host lattices with either the same or with a ligand of similar electronegativity [33]. The theory successfully predicts RE ionization energies in wide band gap sulfides [32] and selenides [33], as shown in Fig. 8.

\section{Excitonic excitation mechanism}

Figure $7 \mathrm{c}$ depicts a new RE excitation mechanism observed for $\mathrm{Yb}$ ion in $\mathrm{ZnS}$ [26]. In this process an ionized carrier is first retrapped by an extended charge transfer state of the ion. A localized bound exciton (BE) state of RE ion $[34,35,38,39]$ is formed. A very complicated recombination patterns may then result [39]. The one shown in Fig. 7c includes a nonradiative recombination of bound exciton due to an energy transfer to $4 f$ core states of the RE ion. Formation of an intermediate $\mathrm{BE}$ state results in a rapid deactivation of $\mathrm{RE}$ emission at increased temperatures, which is an important drawback. 


\section{Processes limiting EL efficiency}

One major deficiency of RE excitation by impact with hot carrier is shown in Fig. 5b. As already explained, one-center Auger process competes with radiative decay of TM, RE ion. Recently interest was focused on processes limiting impact ionization mechanism of RE excitation. These will be discussed here shortly.

IIigh efficiency of impact ionization mechanism requires a rapid retrapping of an ionized carrier. Carrier trapping rates by ionized Eu ions were estimated from ESR investigations of $\mathrm{ZnS}: \mathrm{Eu}$ [24]. Very low cross-sections were concluded from the experiment. These were much lower than those for typical deep trap centers of $\mathrm{ZnS}$. Thus, the presence of any contaminant will deactivate RE excitation.

The second limitation relates to carrier trapping via an excited state of $\mathrm{RE}$ ion. When such state is close to the continuum of the conduction or valence states, RE decay may be destabilized at increased temperatures, or by high electric field, by carrier ionization [30, 31]. Destructive role of the process was evidenced experimentally [22, 40]. For example, Yoshida et al. showed that efficiency of Pr PL in $\mathrm{SrS}: \operatorname{Pr}, \mathrm{K}$ is increased by factor $10^{2}$ compared to that in $\mathrm{ZnS}: \mathrm{Pr}, \mathrm{F}$ [40]. The increase was explained by replacement of the impact excitation mechanism by the impact ionization mechanism [32]. An increased band gap of SrS allows the ionization transition of $\mathrm{Pr}$ ion. IIowever, EL efficiency in $\mathrm{SrS}: \mathrm{Pr}, \mathrm{K}$ increases only 5 times compared to that of $\mathrm{ZnS}: \operatorname{Pr}, \mathrm{F}$. Nearly all gain in the excitation efficiency is lost due to high electric field ionization of the excited state of RE ion [32]. Similar result was reported for Ce in SrS [41].

It was also observed that for some ACTFEL devices a trailing edge emission is few times more efficient than leading edge emission [42]. Such difference was not observed for $\mathrm{Mn}$ or $\mathrm{Tb}$ activated $\mathrm{ZnS}$, i.e., when impact excitation mechanism is responsible for EL excitation. By leading and trailing edge emission we mean here light emission induced by front and edge of the voltage pulse applied to the active layer. The only difference between these two emissions is strength of the electric field in the active layer. A trailing edge emission is induced in the low electric field region. Electrons trapped at shallow interface states during leading edge are remitted and diffuse back to the phosphor where they can recombine at ionized RE centers. Recently a significant improvement of ACTFEL luminance was reported for multilayered $\mathrm{ZnS} / \mathrm{SrS}$ :Ce structures [42]. In a multilayered structure introduction of additional interfaces, i.e., of additional trapping states, strongly enhances a trailing edge emission and thus EL luminance. A further increase in ACTFEL performance is expected due to this new structure [5]. It may also allow for preparing new type white emission EL structures when Tb doped $\mathrm{ZnS}$ will be layered with Ce and Eu doped SrS.

\section{Conclusions}

A rapid progress observed in the field of ACTFEL structures is due to perfecting of two EL excitation mechanisms. On one hand different RE molecules are tested to increase impact excitation cross-sections. On other hand, a progress in manufacturing of stable thin films of $\mathrm{SrS}$ and $\mathrm{CaS}$ enables practical utilization of 
the new impact ionization mechanism of EL excitation. This led to constructing of new efficient blue and white ACTFEL devices. Efficiency of the new devices ensures that multicolor ACTFEL displays can soon be produced.

\section{References}

[1] G. Destriau, J. Chim. Phys. 33, 587 (1936).

[2] T. Inoguchi, M. Takeda, Y. Kalikara, Y. Nakata, M. Yoshida, in: SID Intern. Symp. Dig. 1974, Society for Information Display, Los Angeles 1974, p. 86.

[3] C.N. King, in: SID, Seminar Lecture Notes, Anaheim 1988, Vol. 1, 2 A2.

[4] R.T. Tuenge, in: Electroluminescence, Proc. 6th Intern. Workshop Electroluminescence, Eds. V.P. Singh, J.C. McClure, Cinco Puntos Press, El Paso 1992, p. 173.

[5] H. Kobayashi, in: Electroluminescence, Proc. Gth Intern. Workshop Electroluminescence, Eds. V.P. Singh, J.C. McClure, Cinco Puntos Press, El Paso 1992, p. 179.

[6] M. Leskelä, L. Niinistö, Mater. Chem. Phys. 31, 7 (1992).

[7] J. Schaffer, F. Williams, Phys. Status Solidi 38, 657 (1970).

[8] D. Hommel, W. Busse, II.-E. Gumlich, D. Suisky, J. Röseler, K. Świątek, M. Godlewski, J. Cryst. Growth 101, 393 (1990).

[9] H. Kobayashi, S. Tanaka, H. Sasakura, Y. Hamakawa, Jpn. J. Appl. Phys. 13, 1110 (1974).

[10] W. Iloogenstraten, Philips Res. Repts. 13, 515 (1958).

[11] C.S. Kang, P.B.P. Phipps, R.II. Bube, Phys. Rev. 156, 998 (1967).

[12] D.C. Krupka, J. Appl. Phys. 43, 476 (1972).

[13] N.T. Gordon, J.W. Allen, Solid State Cornmun. 37, 1441 (1981).

[14] A. Suchocki, J.M. Langer, Phys. Rcv. B 39, 7905 (1989).

[15] D.C. Krupka, M.M. Rochkind, J. Appl. Phys. 43, 194 (1972).

[16] D.C. Krupka, D.M. Mahoney, J. Appl. Plyss. 43, 2314 (1972).

[17] T. Ogura, A. Mikami, K. Tanaka, K. Taniguchi, M. Yoshida, S. Nakajima, Appl. Phys. Lett. 48, 1570 (1986).

[18] K. Okamoto, T. Yoshimi, S. Miura, in: Electroluminescence, Springer Proc. in Physics, Vol. 38, Eds. S. Shionoya, H. Kobayashi, Springer, Berlin 1989, p. 139.

[19] Y. Charreire, A. Marbeuf, G. Tourillon, M. Leskelä, L. Niinistö, E. Nykänen, P. Soininen, O. Tolonen, J. Electrochem. Soc. 139, 619 (1992).

[20] J.W. Allen, in: Electroluminescence, Springer Proc. in Physics, Vol. 38, Eds. S. Shionoya, H. Kobayashi, Springer, Berlin 1989, p. 10.

[21] S. Tanaka, H. Yoshiyama, Y. Mikami, J. Nishiura, S. Ohshio, H. Deguchi, H. Kobayashi, Appl. Phys. Lett. 50, 119 (1987).

[22] S. Tanaka, S. Ohshio, J. Nishiura, H. Kawakami, H. Yoshiyama, H. Kobayashi, Appl. Phys. Lett. 52, 2102 (1988).

[23] R.S. Title, Phys. Rev. Lelt. 3, 273 (1959).

[24] M. Godlewski, D. Ilommel, Phys. Status Solidi A 95, 261 (1986).

[25] K. Świątek, M. Godlewski, D. Iommel, Phys. Rev. B 42, 3628 (1990).

[26] H. Przybylińska, K. Świątek, A. Stąpor, A. Suchocki, M. Godlewski, Phys. Rev. B 40, 1748 (1989). 
[27] K. Świątek, M. Godlewski, D. Hommel, Phys. Rev. B 43, 9955 (1991).

[28] H. Zimmermann, R. Boyn, Phys. Status Solidi B 135, 379 (1986).

[29] K. Świątek, M. Godlewski, J. Lumin. 53, 406 (1992).

[30] M. Ando, Y.A. Ono, J. Appl. Phys. 68, 3578 (1990).

[31] K. Świątek, M. Godlewski, D. Hommel, M. Leskelä, L. Niinistö, E. Nykanen, P. Soininen, M. Tiitta, Acta Polytechn. Scand. Ser. Appl. Phys. 170, 237 (1990).

[32] K. Świątek, A. Suchocki, M. Godlewski, Appl. Phys. Lett. 56, 195 (1990).

[33] K. Świątek, M. Godlewski, Acta Phys. Pol. A 77, 95 (1990).

[34] M. Godlewski, K. Świątek, J. Cryst. Growth 117, 634 (1992).

[35] M. Godlewski, in: Proc. MRS Spring Meeting, San Francisco, 1992, MRS Symp. Proc., Vol. 262, Eds. S. Ashok, J. Chevallier, K. Sumino, E. Weber, Materials Research Society, Pittsburgh 1992, p. 513.

[36] K.L. Vander Sluis, L.J. Nugent, J. Chem. Phys. 60, 1927 (1974).

[37] C.K. Jörgensen, Mol. Phys. 5, 3 (1962).

[38] M. Godlewski, in: The Second International School on Excited States of Transition Elements, Karpacz 1991, Eds. W. Stręk, W. Ryba-Romanowski, J. Legendziewicz, B. Jeżowska-Trzebiatowska, World Scientific, Singapore 1992, p. 75.

[39] M. Godlewski, in: Proc. Winter Symp. on Rare Earth Spectroscopy, Karpacz 1993, Acta Phys. Pol. A, in press.

[40] M. Yoshida, K. Tanaka, K. Taniguchi, T. Yamashita, Y. Kakihara, T. Inoguchi, in: SID Intern. Symp. Dig. 1980, Society for Information Display, Los Angeles 1980, p. 106.

[41] R.H. Mauch, in: Conf. Rec. of Symp. on Flat Panel Displays, Osaka 1991, p. 6.

[42] K.O. Velthaus, R.H. Mauch, H.W. Shock, S. Tanaka, K. Yamada, K. Ohmi, H. Kobayashi, in: Electroluminescence, Proc. 6th Intern. Workshop Electroluminescence, Eds. V.P. Singh, J.C. McClure, Cinco Puntos Press, El Paso 1992, p. 187. 